\title{
DE INICIANTES A VANGUARDISTAS: O USO DE TECNOLOGIAS DIGITAIS POR JOVENS PROFESSORES
}

\author{
V. REIS ${ }^{1}$, G. M. LUNARDI-MENDES ${ }^{2}$ \\ ${ }^{1}$ Instituto Federal de Santa Catarina, ${ }^{2}$ Universidade do Estado de Santa Catarina \\ valdeci.reis@ifsc.edu.br*
}

Submetido 22/07/2016 - Aceito 05/02/2018

DOI: $10.15628 /$ holos.2018.4867

\begin{abstract}
RESUMO
Compreender os usos que jovens professores fazem das tecnologias digitais em sala de aula é um dos desafios deste texto. Para isso, o artigo discute três perfis: iniciantes, moderados e vanguardistas. A partir dos resultados, que são um recorte de uma pesquisa realizada no âmbito do Mestrado em Educação, apresentamos aqui os desafios e as estratégias do uso das TICs por jovens professores. A pesquisa qualitativa (MINAYO, 2014) com abordagem etnográfica virtual (MATTOS, 2011; SALES, 2012), fez uso da técnica Snowball (GOODMAN, 1961; DEWES, 2013). O estudo problematiza as narrativas de doze jovens docentes à luz de temas como ubiquidade (SANTAELLA, 2016; 2013; 2004; BURBULES, 2014), desafios da docência na era
\end{abstract}

digital (CASTELLS, 2015; KERCKHOVE, 2016), e integração das TICs na prática pedagógica (BONILLA E PRETTO, 2015). O estudo conclui que os jovens professores tendem a usar com mais intensidade as tecnologias em situação de aula, mas isso não está relacionado apenas ao fato deles serem usuários imersos de artefatos tecnológicos na sua vida pessoal. 0 fator principal que impulsiona esses docentes a desenvolverem práticas pedagógicas inovadoras, especificamente no caso estudado, está relacionado à aproximação que eles tiveram com as TICs na licenciatura e o aprofundamento dessa temática via cursos extracurriculares ou pós-graduação.

PALAVRAS-CHAVE: Aprendizagem Ubíqua, Docência, Ciberespaço, Aplicativos Digitais.

\section{FROM BEGINNERS TO VANGUARDISTS: THE USE OF DIGITAL TECHNOLOGIES BY YOUNG TEACHERS}

\begin{abstract}
To understand the uses that young teachers make of digital technologies in the classroom is one of the challenges of this text. For this, the article discusses three user profiles: beginner, moderate and vanguardists. From the results, which are part of a research carried out within the Master in Education, it is presented here the challenges and strategies of ICT use by young teachers. The qualitative research (MINAYO, 2014) with virtual ethnographic approach (MATTOS, 2011; SALES, 2012), made use of the Snowball technique (GOODMAN, 1961; DEWES, 2013). The study discusses the narratives of twelve young teachers in the light of issues such as ubiquity (SANTAELLA, 2016; 2013; 2004;
\end{abstract}

BURBULES, 2014), challenges of being teacher in the digital era (CASTELLS, 2015; KERCKHOVE, 2016), and integration of ICT in pedagogical practices (BONILLA AND PRETTO, 2015). This study concludes that young teachers tend to use more intensely the technology in classroom situation, but this is not related only to the fact that they are immersed users of technological artifacts in their personal life. The main factor driving these teachers to innovate in their teaching practices, specifically in the case studied, is related to the approach they had with ICT during the licentiateship course, as well as further development of this theme via extracurricular or postgraduate courses.

KEYWORDS: Ubiquitous Learning, Teaching, Cyberspace, Digital Apps. 


\section{INTRODUÇÃO}

Discutir a educação na contemporaneidade implica, necessariamente, analisar os agentes educacionais na sociedade em que eles estão imersos, uma sociedade tecnológica, interconectada por redes digitais, imbricada por um conjunto de sistemas que convergem em microeletrônica: softwares, hardwares, telecomunicações e radiodifusão.

Na perspectiva sociológica, a sociedade atravessa um novo estágio global. Castells (2002) classifica de sociedade informacionalista; Santaella (2013) prefere o termo sociedade ubíqua. Esse novo movimento começou por volta de 1970, com a convergência de várias tecnologias analógicas. A possibilidade de transformar várias fontes de informações - textos, áudios, vídeos em bytes de 0 a 1 , disponibilizando-as em servidores e data center que permitem a comunicação com redes telemáticas, deu início a era virtual.

Esse cenário tenciona a relação docente no processo de ensinar e produzir conhecimento, pois as forças e agendas que atuam sobre o professor em cada época materializam sua identidade docente e caracterizam determinado momento da cultura escolar. Uma relação, muitas vezes, permeada pela dualidade entre manter a tradição e o poder do ensinar ou dividir o protagonismo do processo de aprendizagem com os estudantes, na busca da construção participativa do conhecimento. Segundo Dussel (2011), a posição dos docentes frente ao uso das Tecnologias Digitais, como recurso para o ensino e aprendizagem, vem sofrendo mudanças céleres que estão diretamente vinculadas à sua participação, ou não, na cultura digital.

Sales (2013) advoga que a juventude ciborgue - jovens que estão em várias redes sociais, que utilizam inúmeros artefatos tecnológicos - desafia e tenciona um novo currículo escolar. A pesquisadora entende currículo como um processo de "formação de sujeitos, de produção de identidades e subjetividades ou de subjetivação" (p. 194).

As tecnologias digitais têm chegado à escola por diferentes vias: programas de inclusão digital, promovidos por órgãos governamentais; fundações ligadas ao terceiro setor; indústrias de tecnologia da comunicação; estudantes mergulhados em uma sociedade digital que acabam levando seu artefato tecnológico para a sala de aula; professores que tentam inovar na mediação pedagógica.

Todos esses fatores contribuem para que o currículo escolar seja alvo do imperativo ciborgue, o que Sales (2013) define como uma realidade que surge da:

\footnotetext{
complexificação e transformação dos planejamentos e das práticas curriculares por meio da intensiva e extensiva incorporação/fusão com as tecnologias digitais. A sensação provocada é de que não há escape: estamos inevitavelmente submetidos à presença das tecnologias digitais nos currículos escolares (p. 194).
}

Diante desse panorama, o manifesto ciborgue, de Donna Haraway, escrito em 1986, na Califórnia, ainda é extremamente contemporâneo para debatermos as especificidades dos jovens nascidos em uma sociedade em rede, que vivem suas vantagens e desvantagens, problemas e soluções, objetividades e subjetividades de uma cultura digital.

Haraway (2009) define a metáfora do Ciborgue como "um organismo cibernético, um híbrido de máquina e organismo humano" (p. 36). Trata-se de uma engenharia tecnológica que pode atuar desde a restauração de um órgão, bem como melhorar a capacidade do humano de se comunicar, trabalhar e atuar no seu círculo social via artefatos tecnológicos.

Essa intrínseca relação com redes, plataformas digitais e artefatos tecnológicos é o que Haraway (1991) chama de ciborguização. Uma relação recíproca que temos com os organismos 
digitais e estes contribuem ampliando nossa capacidade de comunicação, de trabalho, de estudo, de nos relacionarmos virtualmente.

Embora o conceito Ciborgue seja utilizado pela autora como uma metáfora, Haraway defende que essa relação recíproca que estamos estabelecendo com a tecnologia é uma linha extremamente tênue, que pode nos conceder benefício, bem como alguns sortilégios. Intensificação do trabalho, conflitos entre o privado e o social, confusões entre o profissional e o pessoal são alguns malefícios que essa relação pode nos trazer.

Pesquisas recentes que analisaram a gestão e os usos das tecnologias móveis em escolas públicas brasileiras (QUARTIERO e FANTIN, 2014; QUARTIERO, BONILLA e FANTIN, 2015; LUNARDI-MENDES, SOUZA-NETO e REIS 2015) constataram que um dos maiores desafios para o uso das tecnologias na mediação pedagógica era a insegurança por parte dos docentes. De acordo com tais pesquisas, entre as falas recorrentes dos professores entrevistados, destacamse: 1) Confronto geracional entre docentes e educandos; 2) Formação inadequada para os usos das TICs; 3) Falta de suporte e infraestrutura na escola; 4) Falta de habilidade para manusear tais artefatos.

Este artigo é parte dos resultados de uma pesquisa realizada no âmbito do Mestrado em Educação, com o objetivo de compreender como jovens professores nascidos em uma sociedade em rede incorporam e usam as tecnologias digitais na sala de aula. O exercício da sua docência é diferente? Como ela acontece?

Partimos da premissa de que a popularização da internet no Brasil está estabelecendo novos processos subjetivos entre os usuários interconectados por redes. As interações proporcionadas pelas redes telemáticas tencionam uma nova forma de ser e de viver em sociedade, reconfigurando o papel de professores e alunos no espaço social e virtual.

Atualmente, na sociedade brasileira, há um intenso debate sobre o que é ser jovem. Quando mencionamos a categoria 'Jovem Professor', estamos nos referindo a todas as pessoas entre 18 e 29 anos que atuam como educadores. Tal recorte foi realizado com base nos parâmetros do Estatuto Brasileiro da Juventude, bem como na análise das políticas públicas promovida pelo Governo Federal nos últimos 16 anos - criação do Conselho Nacional da Juventude, criação da Secretaria Nacional da Juventude, criação do Programa Nacional de Inclusão de Jovens. Ao observar os documentos, leis e decretos que norteiam a política nacional da juventude brasileira, é possível constatar que todas as normativas denominam como jovem a faixa etária entre 15 e 29 anos.

Em relação aos adolescentes de 15 a 18 anos, o Estatuto da Juventude esclarece que algumas especificidades são regidas pela Lei no 8.069, de 13 de julho de 1990, que institui o Estatuto da Criança e do Adolescente, bem como outras leis específicas de proteção laboral, não se aplicando o que está previsto no Estatuto da Juventude.

No recorte que aqui apresentamos, o objetivo é compreender jovens professores tecnológicos nascidos em uma sociedade em rede desenvolvem sua docência; refletir como esse professor ubíquo (imerso no ciberespaço, que produz e consome mídias) realiza a gestão dos artefatos tecnológicos na sua sala de aula; evidenciar os conflitos e ambivalências em exercer a docência na era digital. Esses aspectos são fundamentais para compreender este sujeito e sua relação com as tecnologias digitais e, com isso, trazer contribuições para a discussão sobre os desafios da educação na contemporaneidade.

Para tanto, organizamos o artigo, apresentando inicialmente a metodologia utilizada, em seguida, apresentamos as narrativas que os jovens professores teceram em relação ao uso que eles fazem das tecnologias digitais na sala de aula. Finalizamos o texto tecendo algumas reflexões sobre os desafios da docência na era digital. 


\title{
2 EM BUSCA DO JOVEM PROFESSOR: CAMINHOS METODOLÓGICOS
}

Levando em consideração que essa pesquisa buscou compreender a docência de jovens professores, a priori conectados em rede, evidenciando as contradições, os paradoxos, as ambivalências e os inacabamentos, optou-se pela abordagem etnográfica virtual.

Tal escolha trata-se de um processo ao mesmo tempo enraizado no sujeito observador e no sujeito observado. Assim, pesquisador e pesquisados são sujeitos ativos, assumindo uma postura interativa no processo da pesquisa. Mattos destaca três aspectos fundamentais nesta abordagem:

\begin{abstract}
1) preocupar-se com uma análise holística ou dialética da cultura; 2 ) introduzir os atores sociais com uma participação ativa e dinâmica e modificadora das estruturas sociais; 3) preocupar-se em revelar as relações e interações significativas de modo a desenvolver a reflexividade sobre a ação de pesquisar, tanto pelo pesquisador quanto pelo pesquisado (2011, p. 49).
\end{abstract}

De acordo com a autora, o termo etnografia tem origem no grego. Uma tradução literal seria: escrever sobre (grafi) um determinado grupo ou sociedade específica (etno). Essa abordagem começou a ganhar força na transição do século XIX para o século XX, na tentativa de compreender minuciosamente as especificidades de uma determinada cultura.

Tanto a etnografia mais tradicional (GEERTZ, 1989; LÉVI-STRAUSS, 1988) quanto a mais contemporânea (ERIKSON, 1992; WOODS, 1986; MEHAN, 1992; WILLIS, 1977), se preocupam em compreender como os sujeitos investigados agem dentro de um grupo social. Trata-se de uma observação que busca analisar, documentar, monitorar uma determinada ação, na tentativa de compreender o cotidiano do grupo em estudo.

Com a difusão da internet e dos artefatos tecnológicos permitindo a interação em rede a todo o momento e em qualquer espaço, novas ramificações da etnografia surgiram: etnografia digital, etnografia on-line, etnografia na internet, etnografia conectiva, etnografia da rede, ciberetnografia, netnografia - são algumas denominações de uma etnografia específica que acontece nos ambientes virtuais (SALES, 2012).

No geral, a etnografia virtual é um processo de investigação que acontece no ciberespaço a partir da formulação de uma rede. A tessitura dessa rede depende da conexão de nós - pessoas - que tenham alguma relação entre si. O princípio básico para conexão desses pontos é o objetivo do estabelecimento da rede, bem como a adesão dos participantes.

A pesquisa fez uso de algumas técnicas da etnografia virtual, sobretudo na aplicação da fase inicial da snowball, técnica de pesquisa também conhecida como 'bola de neve' (GOODMAN, 1961). Durante a execução outros protocolos de pesquisa utilizados foram: observação na rede social, aplicação da snowball e web entrevista semiestruturada.

Dewes (2013), analisando a técnica snowball a partir dos estudos de Goodman (1961), enfatiza os cuidados que um pesquisador precisa ter na constituição de um grupo por meio da técnica bola de neve. Para o autor, a "amostragem em bola de neve pressupõe que há uma ligação entre os membros da população dado pela característica de interesse, isto é, os membros da população são capazes de identificar outros membros" (p. 10).

Todavia, algumas etapas precisam ser seguidas rigorosamente para que a população possa trazer dados relevantes ao pesquisador. Um dos pontos mais estratégicos desse processo é a constituição da semente da amostra populacional, ou seja, encontrar pessoas com as características da população-alvo do estudo. 
O autor considera que a seleção da semente é fundamental, pois é ela que vai dar a tonalidade da população investigada. É a partir da semente que surgirão todos os outros indivíduos da pesquisa.

Outra metáfora que aparece nas análises de Dewes (2013) para descrever as especificidades da técnica bola de neve é a onda. A escolha da semente é processo inicial da pesquisa. Concluída essa etapa, o percurso metodológico forma a onda zero.

\footnotetext{
- Inicia-se o processo pedindo a cada semente que indique o contato de $\mathrm{x}$ outros indivíduos que eles consideram ser membros da população-alvo.

- A onda um é formada pelos contatos indicados pelos indivíduos da onda zero que fazem parte da população-alvo e que não fazem parte da onda zero.

- A onda dois é formada pelos contatos indicados pelos indivíduos da onda um que fazem parte da população alvo e que não fazem parte da onda zero nem da onda um.

- O processo segue até que o tamanho da amostra desejado seja alcançado ou então quando uma nova onda não produza um determinado número de contatos novos (DEWES, 2013, p. 11).
}

Embora Goodman (1961) tenha desenhado a formulação matemática da técnica metodológica, este autor não deixou nenhum registro de como deveria ser aplicado esse método. Esses procedimentos foram desenvolvidos pelos seus seguidores (BIERNACKI e WALDORF, 1981). As tensões em torno da aplicação do método bola de neve sempre giram em torno do número ideal de participantes para formar a onda zero. A seleção de poucas sementes para formar essa etapa inicial pode contribuir para que a formação da rede termine nas ondas iniciais. Por outro lado, a seleção de muitas sementes na primeira etapa nem sempre tem se mostrado profícua no percurso metodológico. Dewes (2013) considera que limitar esse número entre 3 e 6 resulta em uma escolha metodológica eficaz.

A aplicação da snowball iniciou com uma observação de cinco meses em três redes sociais digitais: Facebook, Google+ e LinkedIn. A escolha por tais redes sociais levou em consideração um estudo detalhado, divulgado pela Secretaria de Comunicação da Presidência da República (BRASIL, 2014), que apontou os hábitos de consumo de mídia pela população brasileira, bem como as redes sociais com o maior número de filiados no país. De acordo com tal estudo, a rede social Facebook é a primeira em número de filiados, o Google+ ficou na quinta posição e a Linkedln na décima posição.

Nosso objetivo era identificar, através das discussões tecidas nessas redes sociais, jovens professores usuários de artefatos tecnológicos e plataformas digitais na sua vida pessoal e social, mas que também vislumbrassem a tecnologia como uma possibilidade na mediação pedagógica.

Após esta observação, encontramos nas três redes sociais mencionadas, vinte e seis jovens docentes que tinham as características de que a pesquisa necessitava. Era um número extremamente alto para formar a onda zero da snowball. Seguindo as análises de Dewes (2013), limitamos a primeira onda em três docentes.

Para a escolha dos três jovens entre os vinte e seis que estávamos observando nas redes sociais, levamos em consideração o número de postagens em que eles compartilhavam, por exemplo: técnicas para o uso de tecnologias digitais em sala de aula; post relatando uma atividade pedagógica onde os estudantes e os docentes trabalhavam colaborativamente através de alguma plataforma digital; situações de cooperação tecnológica entre docentes e discentes.

De acordo com a imagem 01, a onda zero da snowball, podendo também ser chamada de 'semente da amostra da população', é formada por três jovens professores, a saber: (A0), (BO) e (CO). Após a entrevista, cada participante foi indicando outro contato do seu círculo social. A 
formação das ondas continuou até as entrevistas atingirem uma saturação dos dados, ou seja, na onda três as narrativas dos docentes já não traziam informações inéditas à pesquisa.

Imagem 01: Aplicação das Ondas da Snowball

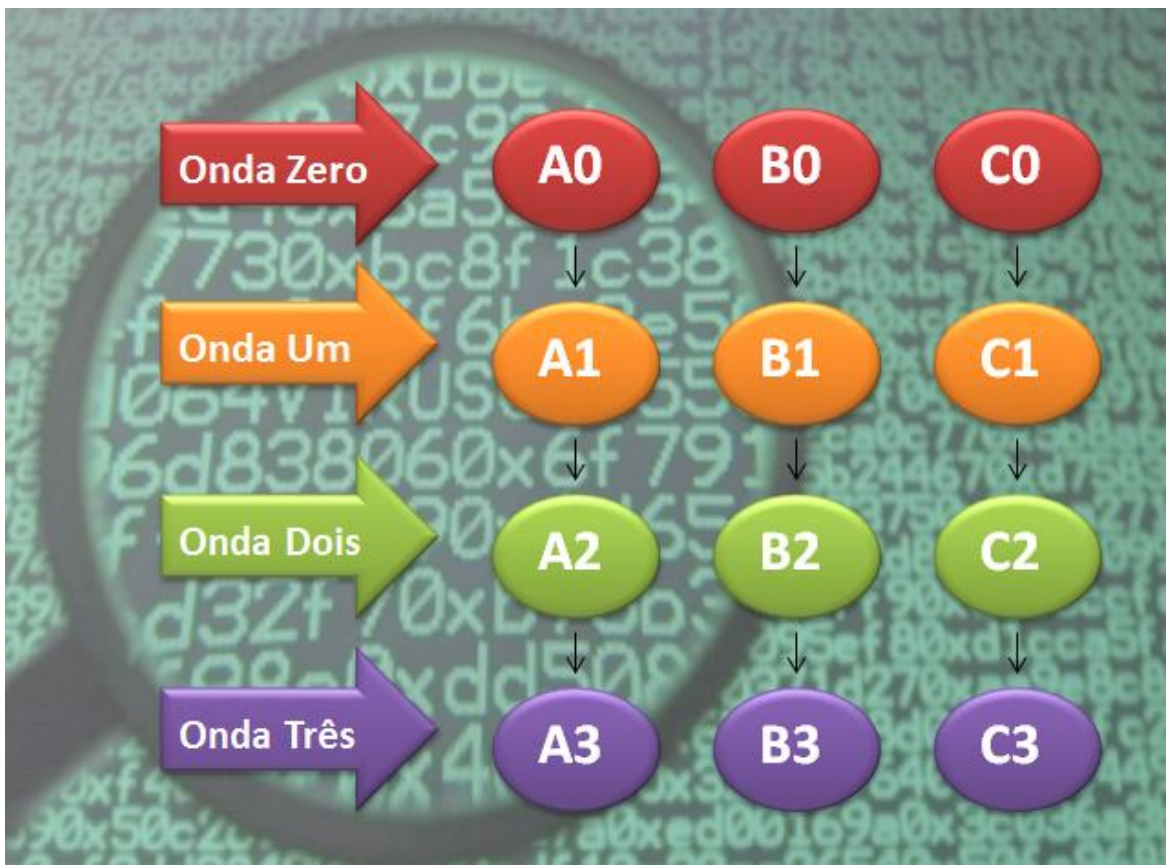

Fonte: Elaboração própria.

Como procedimento de coleta de dados, optamos por aplicar a web entrevista com todos os integrantes do estudo. Como o grupo em análise conta com participantes de diferentes regiões geográficas, a web entrevista semiestruturada se mostrou uma alternativa interessante. Minayo (2014) considera que a entrevista semiestruturada "combina perguntas fechadas e abertas, em que o entrevistado tem a possibilidade de discorrer sobre o tema em questão sem se prender à indagação formulada" (p. 261).

Dentro da abordagem etnográfica, a entrevista semiestruturada é um instrumento significativo para captar informações importantes ao objeto da pesquisa. Esta técnica permite perguntar de modo direto aos investigados (jovens professores) sobre suas experiências, opiniões e preferências a respeito do uso das tecnologias, e da gestão dos processos na instituição educacional. É um dispositivo bastante significativo que ultrapassa a simples função de coleta instrumental de dados.

Minayo (2014) destaca, ainda, que conduzir uma entrevista semiestruturada não é tarefa simples, sobretudo para quem não tem experiência sólida em pesquisas. A autora recomenda algumas etapas para que o pesquisador tenha êxito na ação: "apresentação; menção do interesse da pesquisa; apresentação de credencial institucional; explicação dos motivos da pesquisa; justificativa da escolha do entrevistado; garantia do anonimato e de sigilo; conversa inicial" ( $p$. 263-264).

Dentro da abordagem etnográfica, uma metáfora utilizada por Malinowski (1978) ainda é muito inspiradora para os adeptos dessa metodologia. "O etnógrafo não tem apenas que estender suas redes no lugar correto e esperar pelo que nela cairá. Deve ser um caçador ativo e dirigi-las para sua presa e segui-la até as suas tocas mais inacessíveis" (p. 45). 
É claro que a metáfora utilizada pelo autor se refere à sua experiência etnográfica com os indígenas. Mas o jogo das figuras simbólicas utilizadas na oração trazem uma riqueza de detalhes que podem inspirar pesquisas etnográficas em educação. Sobretudo, a necessidade do etnógrafo em educação manter-se atento aos elementos que surgem durante o processo de investigação; ser capaz de utilizar um estilo mais informal de linguagem; ter uma perspectiva crítica, problematizando pontos de vista conflitantes e divergentes (LÜDKE e ANDRÉ, 1986), aproximando, assim, a abordagem etnográfica com a pesquisa qualitativa em educação. Passaremos na sequência a apresentar os achados resultantes dos encontros virtuais com os jovens professores.

\section{O USO DE TECNOLOGIAS DIGITAIS POR JOVENS PROFESSORES}

Ao analisar qualitativamente as doze narrativas em relação ao uso de tecnologias em situação de aula, foi possível elencar três perfis, a saber: iniciantes, moderados e vanguardistas. Os iniciantes são professores que saíram recentemente da graduação - dois a três anos -, que tiveram alguma disciplina relacionada ao tema, e/ou tiveram contato com as tecnologias digitais por meio da pesquisa ou da extensão universitária. Esses professores vislumbram possibilidades de recursos digitais em situação de aula, todavia, eles são utilizados de forma muito tímida devido à insegurança profissional.

Os moderados utilizam recursos digitais com mais intensidade na sua prática pedagógica. Pelas narrativas, foi possível identificar que planejamento, roteiro e intencionalidade pedagógica são detalhes que precedem ao uso da tecnologia em sala de aula. Em geral, são professores que, durante a graduação, passaram por alguma situação que despertou o interesse pelas TICs (Tecnologias da Informação e Comunicação) - influência de algum professor, curso extracurricular, intercâmbio - e, após a graduação, esses docentes procuraram alguma formação mais aprofundada na área.

Os vanguardistas são os docentes com as práticas pedagógicas mais inovadoras, em geral, tentam explorar produções colaborativas com seus discentes. Estes jovens professores utilizam as tecnologias digitais independentemente da estrutura tecnológica da escola. Outro aspecto a destacar sobre esse grupo é a naturalização do terceiro setor adentrando a escola pública. Conforme suas narrativas, o Governo e as Universidades estão muito distantes dessa discussão, não investem em plataformas e software educativos. Para os vanguardistas, já que alguém está disponibilizando uma tecnologia, é preciso valorizá-la e utilizá-la bem. A seguir apresentaremos a análise das doze narrativas.

\subsection{As narrativas dos Jovens Professores Vanguardistas}

Os jovens professores vanguardistas teceram narrativas muito interessantes sobre práticas pedagógicas colaborativas, literacy digital, e cidadania plena na era digital. Todavia, causou apreensão aos pesquisadores o tema Software Livre, que não foi mencionado nas narrativas. Ao contrário das expectativas do projeto de pesquisa, esses docentes incorporam com muita naturalidade pacotes e plataformas desenvolvidas por fundações ligadas ao terceiro setor.

Questionados sobre o fato de quase todas as plataformas educacionais e Softwares que eles utilizam na sala de aula serem desenvolvidos ou disponibilizados por fundações educacionais, estes docentes justificam suas escolhas uma vez que os governos, de uma forma geral, cruzaram os braços para o desenvolvimento de tecnologia educacional manipulativa. Para alguns, o avanço do terceiro setor é consequência da total ausência do Estado, e, se alguém está 
disponibilizando alguma ferramenta, de acordo com as narrativas docentes, é preciso fazer um bom uso dela.

Ao analisar a fala da Professora B0, fica evidente que o avanço das indústrias de tecnologia da informação, bem como Fundações Educacionais, também acontece por vias institucionais. A docente de matemática discorria sobre o uso da Lousa Digital para o ensino da Geometria e destacava a diferença da Lousa Digital Móvel disponibilizada pelo Ministério da Educação e a Lousa Digital Fixa fornecida por uma empresa de São Paulo.

Quando problematizado o motivo de algumas escolas municipais de Florianópolis possuírem artefatos tecnológicos disponibilizados pelo MEC e outras terem artefatos disponibilizados por indústrias, a docente explicou que a escola participava de um projeto-piloto desenvolvido pela secretaria municipal de educação e a indústria fabricante da Lousa. Segundo a narrativa docente, essa empresa deseja vender um pacote educacional para a Prefeitura de Florianópolis, mas, antes desse contrato ser firmado, as partes envolvidas resolveram fazer um teste-piloto.

A indústria fabricante do artefato instalou a lousa na escola, doou 50 notebooks, e dois carrinhos para carregar as baterias dos artefatos móveis. Pessoas ligadas a uma fundação educacional ofereceram uma formação para o manuseio da Lousa Digital. É extremamente preocupante esse tipo de acordo institucional no âmbito da esfera governamental: empresas doam alguns artefatos, mas comercializam a licença dos softwares.

O fato de docentes com amplo conhecimento em tecnologia da informação e comunicação tratarem essa relação com naturalidade é consequência dos cursos de licenciaturas não promoverem um debate crítico sobre a difusão tecnológica em nossa sociedade. Na rápida aproximação que estes professores tiveram com a temática na graduação, foram apresentados a eles apenas os pontos positivos, a possibilidade de uma aula mais dinâmica e interativa. Faltou, todavia, uma reflexão sobre o lado emblemático da difusão tecnológica.

Os jovens professores vanguardistas estão muito conscientes de que as tecnologias digitais são apenas um suporte para trabalhar um conteúdo abstrato; um suporte para instigar a reflexão; um suporte para promover práticas de interação no processo de ensino aprendizagem. A tecnologia em si, contudo, não modifica nada; tudo depende da intencionalidade pedagógica de quem conduz a aula. Acerca dessa temática, o professor A1 discorre sobre o conceito da Arquitetura Pedagógica,

\footnotetext{
que são as três presenças, a presença do social, a presença do ensino e a presença do cognitivo. Ai nós vamos perceber que a intersecção dessas três presenças é o suporte. Que dizer, as instituições podem oferecer para os professores, e aí nos vamos esquecer o digital, eu posso dar para o professor o melhor livro didático que as editoras já publicaram. Não tendo a presença do ensino, a presença cognitiva, o suporte por si só não vai conduzir uma boa aula. Então para termos uma experiência educacional com êxito nós precisamos focar na tríade da arquitetura pedagógica. E ter muita clareza que o suporte é apenas um dos elementos (sic) (Professor A1).
}

Para esses docentes, as licenciaturas e a formação continuada não precisam se preocupar muito com questões instrumentalistas: como acessar a plataforma? Como fazer o upload? Como fazer o download? Essas questões já estão dadas e existe muito tutorial na internet explicando essas especificidades. De acordo com os entrevistados, a academia deve se preocupar com o desenvolvimento das competências a partir do Big Data, do Ciberespaço e da inteligência coletiva. 
A questão curricular também foi um elemento que apareceu com força em quase todas as narrativas. Segundo os professores, as discussões curriculares não têm privilegiado a integração das tecnologias na sala de aula:

Eu vejo as tecnologias chegando à escola, mas eu não vejo a escola se modificando. A questão mais emblemática para mim é o currículo. A escola insiste em manter o processo de ensino fragmentado, em caixas isoladas. As tecnologias apontam para outra direção, para o ensino colaborativo, para a interdisciplinaridade, mas são poucos os que conseguem fazer isso (sic) (Professora A0).

Me assusta um pouco o Ministério (da Educação) achar que o Brasil precisa de uma Base Nacional Comum. Se nós temos "Brasils", "Brasilidades", e aí nos temos um currículo nacional? Isso é totalmente contrário à perspectiva de currículo! O Currículo, ele nasce para aquele contexto, e se o Brasil tem contextos diversos, como é que eu vou ter uma base nacional comum? (sic) (Professor A1).

Eu acredito que uma primeira questão é revisar o currículo, e não revisar o currículo na perspectiva da Base Nacional Comum, particularmente eu acho que isso não funciona. Mas isso é bem a minha visão. Eu acho que é preciso revisar o currículo a partir da realidade daquela escola, o que aquela escola precisa para se integrar melhor com a sociedade? E aí o Blog, por exemplo, pode dar conta. Mas o que aquela escola precisa para se integrar com a sociedade na perspectiva dos atores sociais que compõem o processo de ensino aprendizagem? A família, por exemplo! E daqui a pouco nós vamos chegar à conclusão de que não é necessário uma plataforma tão complexa. Eu acho que nós temos dois caminhos em curso, ou se tenta inovar muito e o aluno fica um pouco perdido e o professor inseguro, ou se tenta fazer algo da realidade analógica que já existia. Eu acredito que como educadores nós precisamos encontrar um meio termo para isso, um caminho intermediário. Quais são as ferramentas disponíveis que eu tenho e o que eu consigo fazer a partir delas? Eu acho que é um pouco diminuir a complexidade para otimizar a interação, eu acho que esse é caminho que tem que ser buscado independentemente da instituição em que isso está ocorrendo (sic) (Professora BO).

A Pesquisadora Argentina Inês Dussel (2013; 2010) tem desenvolvido contribuições relevantes sobre os desafios do currículo na contemporaneidade. A autora analisa o currículo sob a metáfora da autoridade cultural. Nessa perspectiva, a proposta curricular é pensada levando em consideração aspectos culturais, econômicos e sociais em que a instituição educacional está inserida.

Se recorrermos a uma literatura mais clássica sobre a questão curricular, vamos constatar que inovações e mudanças curriculares são aspectos com um longo trajeto a ser percorrido na esfera institucional. Young (2010) afirma que:

\footnotetext{
A ideia de um "currículo do futuro" continua a ser isso mesmo - uma tendência e uma ideia que dificilmente encontramos em qualquer forma institucional. É inquestionável que ela ainda tem um longo caminho a percorrer no que diz respeito ao estabelecimento de uma base de confiança que demonstre que se tratará de uma maneira de promover aprendizagens de alta qualidade. Se quisermos que cumpra as promessas que são feitas em seu nome, será necessário criar novas formas de associação e de confiança e novos tipos de especialistas. A tensão atual entre os dois modelos curriculares, que não está resolvida, dá origem, na melhor das hipóteses, a modificações práticas do "currículo do passado". Tais alterações evitam estabelecer novas redes de especialistas que tenham em conta as mudanças econômicas globais, sem que percam a autonomia crucial permitida pelas velhas disciplinas (p. 180).
} 
Aprimorar a proposta curricular significa, necessariamente, empreender esforços para resolver as tensões oriundas entre essas diferentes lógicas e perspectivas. Trata-se de um trabalho hercúleo e que, aparentemente, não parece ter fim. É uma ação que não gera mudanças definitivas. Há que se construir tais mudanças cotidianamente, a partir dos atores sociais que compõem a instituição de ensino.

Outro termo muito citado entre os jovens professores vanguardistas foi a 'literacy digital'. O Professor A1 destaca, em sua narrativa, que, quando ele vai fazer alguma atividade de integração com as mídias com uma turma nova, uma dinâmica à qual ele sempre recorre é a seguinte: "o aluno que me trouxer primeiro o e-mail do Barack Obama, ganha um ponto na média". A1 esclarece que, em cada dinâmica, ele vai alternando o Chefe de Estado, e acredita que, com essa atividade, é possível analisar o nível de 'literacy digital' dos alunos da turma.

O conceito de 'literacy digital', para esses docentes, está muito próximo de uma alfabetização midiática para o exercício da cidadania:

\begin{abstract}
Vamos pegar a sociologia como exemplo, e se esse professor se der conta que ele pode trabalhar as manifestações que estão ocorrendo a favor e contra do impeachment a partir da timeline do facebook da sua turma, já é um grande avanço para o aluno. E aí nós voltamos para a questão da cidadania, a timeline do meu facebook não é a verdade sobre os fatos, e se que é a verdade que existe sobre os fatos. Tem um processo de seleção dos conteúdos, então dar consciência sobre isso para o aluno é tão importante como no século passado era dar consciência sobre o ensino religioso, era importante dar consciência sobre os fatos históricos. É muito complexa essa visão, e aí eu jogaria isso no arcabouço do termo literacy digital. É uma área que tem ganhado muito chão. Há uma escola da França que trabalha muito com esse termo. Mas assim, vamos vencer essa perspectiva utilitarista, vamos fazer o aluno ter consciência, vamos fazer ele de fato perceber o que está por trás da timeline do facebook! É preciso perceber o que está por trás de um comentário que um determinado aluno traz para sala de aula sobre as manifestações que estão ocorrendo pelo país. Como o professor pode trabalhar isso de uma forma mais ideal? (sic) (Professor A1).
\end{abstract}

A1 acredita que é através da educomunicação, ou seja, trabalhar em uma perspectiva para que os estudantes desenvolvam uma consciência de como os conteúdos são produzidos e disseminados pelos meios de comunicação. Posição que também é compartilhada pela docente A0, que citou várias vezes, em sua narrativa, a dialogicidade de Paulo Freire. Para esta docente, uma vez que os adolescentes têm acesso, por meio do seu Smartphone, a uma avalanche de informações, o educador precisa estar atento, em sala de aula, aos comentários que eles trazem para a escola, que precisam ser problematizados. Nesse sentido, a docente acredita que a obra de Paulo Freire ainda é muito atual.

Recorrendo ao livro mencionado pela docente na entrevista, para Paulo Freire (1976), "ser dialógico é vivenciar o diálogo, é não invadir, é não manipular, é não 'sloganizar'. O diálogo é o encontro amoroso dos homens que, mediatizado pelo mundo, o pronunciam, isto é, o transformam e, transformando-o, o humanizam" (p. 43). Este livro, escrito durante o exílio do educador brasileiro no Chile, tornou-se, mais tarde, uma das literaturas-base da educomunicação, um campo de intervenção que visa refletir, dialogar e pesquisar a interface educação/comunicação.

Citelli e Costa (2011) esclarecem que o campo epistemológico da educomunicação vai muito além de pontos e intersecções entre as áreas educação e comunicação. Para os autores, as novas tecnologias que estão adentrando os espaços educacionais, as redes sociais digitais amplamente difundidas entre os jovens, as narrativas tecidas pelos meios de comunicação tradicionais e alternativos são objetos de estudo da educomunicação. 
Em síntese, os autores afirmam que:

\begin{abstract}
A educomunicação como uma área busca pensar, pesquisar, trabalhar a educação formal, informal e não formal no interior do ecossistema comunicativo. Posto de outro modo, a comunicação deixa de ser algo tão somente midiático, com função instrumental, e passa a integrar as dinâmicas formativas, com tudo o que possa ser carreado para o termo, envolvendo desde os planos de aprendizagem (como ver televisão, cinema, ler jornal, a revista; realização de programas na área do audiovisual, da internet), de agudização da consciência ante a produção de mensagens pelos veículos; de posicionamento perante um mundo fortemente editado pelo complexo industrial dos meios de comunicação (CITELLI e COSTA, 2011, p. 8).
\end{abstract}

Uma prática educativa na perspectiva da educomunicação pressupõe outra postura nos processos de ensino aprendizagem. Adotando uma postura mais atuante no exercício da cidadania, o estudante deixa de ser apenas um receptor de informações, passando a refletir ética e esteticamente, além de ser protagonista na produção do conhecimento junto com o professor.

Por fim, outro recurso em comum utilizado pelos jovens professores vanguardistas é a produção de audiovisual a partir do artefato tecnológico do estudante. A0 recorre à produção de vídeos para fixar um conteúdo ou tema estudado na disciplina de matemática. A docente acredita que essa técnica permite que os estudantes explorem a aplicabilidade do conceito estudado no cotidiano. Perspectiva parecida também é defendida por B0, docente da mesma disciplina.

Já $A 1$, docente de sociologia, entende a produção audiovisual como um complemento das reflexões tecidas na sala de aula.

Nós não fizemos mais apresentação de trabalho em sala de aula. Então o aluno ou o Grupo grava um vídeo que pode ser através do Hangouts, uma ferramenta oferecida pelo Google e compartilha com a turma. Esse compartilhamento pode se dar na plataforma Moodle, no whatsapp, no grupo do face. E os colegas fazem considerações, então esse é um momento que nós conseguimos tirar do encontro presencial, mesmo que o curso seja todo presencial. Por que a legislação nos permite explorar os $20 \%$ do presencial em EaD, e eu acho que isso funciona. Principalmente na educação profissional tecnológica, aqui no Instituto Federal, eu não vejo mais sentido chamar um aluno em uma quinta ou sexta-feira à noite, dependendo da sua área de atuação, tirá-lo da sua residência, para ele assistir apresentação de trabalho dos colegas, eu acredito que o Ciberespaço nos permite fazer isso a distância e com resultados muito melhores (sic) (Professor A1).

A narrativa do docente $A 1$ mostra-nos uma mudança estrutural na condução da prática docente. A apresentação de trabalhos é via ciberespaço e o aluno pode estar em qualquer lugar, em sua residência, na casa do amigo, no parque, mesmo que o curso seja totalmente presencial. Essa forma de promover interação pedagógica se aproxima bastante do termo Aprendizagem Ubíqua - um conceito que tem sido explorado em profundidade por Santaella (2013) e Burbules (2014). Tal perspectiva pressupõe que o processo de ensino aprendizagem pode acontecer a qualquer momento, em qualquer lugar, mediante o auxílio das infovias do Ciberespaço.

Por mais interessante e inovador que isso possa parecer, é preciso destacar que não é uma prática simples de ser executada. O docente precisa ter muito claro quais objetivos pedagógicos ele almeja com tal ação, bem como o perfil e o grau de 'literacy digital' que os seus discentes dispõem para executar tal tarefa. Em uma turma em que os estudantes não são usuários da rede mundial de computadores, essa prática pedagógica ficaria comprometida. 
Ao analisar com mais profundidade a narrativa dos três jovens docentes vanguardistas A0, A1, B0 - que descreveram a produção de vídeo a partir do smartphone do estudante, é possível constatar que esses docentes lecionam em escolas que possuem Wi-Fi em todas as salas de aulas, o que, de certo modo, facilita a integração do artefato móvel do discente na prática pedagógica. As três escolas possuem Lousa Digital. As três escolas possuem laboratórios específicos da sua disciplina. Nesse espaço, o docente dispõe de vários recursos de tecnologia manipulativa para trabalhar determinado conteúdo. A partir da estrutura existente na escola, este professor desenvolve um planejamento pedagógico. Dependendo do objetivo, ele recorre a alguma mídia para explorar com mais intensidade o conteúdo curricular.

\subsection{As narrativas dos Jovens Professores Moderados}

O smartphone foi o artefato tecnológico mais citado por esse grupo de professores, e o tema aprendizagem ubíqua também apareceu com força nas narrativas, porém acompanhadas de alguns dilemas. Para esses docentes, a tecnologia encurta muitos caminhos e facilita muita coisa, porém a questão mais emblemática é que estamos perdendo a noção do limite entre o profissional e o pessoal. Para a professora C2, essa confusão acontece não apenas com os adolescentes, mas com colegas de trabalho também.

\footnotetext{
Recentemente, agora no sábado de carnaval, eram duas da madrugada, eu estava no baile de carnaval e a Coordenadora Pedagógica estava no Grupo do Whatsapp debatendo as deliberações da última reunião com a coordenação do curso (risos), te juro, posso te mostrar isso (risos). Então eu vejo que as pessoas estão perdendo um pouco da noção de como usar a tecnologia (sic) (Professora C2).
}

Ao analisar a narrativa da Professora C2, fica evidente um desconforto com a avalanche de questionamentos a que ela tem que responder via redes sociais. A docente explicita que, durante o fim de semana e feriados, seus alunos enviam inúmeros questionamentos via Whatsapp sobre assuntos da disciplina, assuntos esses que, segundo a entrevistada, já foram exaustivamente debatidos na sala de aula.

A docente de Geografia desconfia que uma das razões de haver tantos questionamentos de assuntos já abordados na sala de aula é por conta do fato de que, enquanto ela explica o conteúdo, os alunos estão plugados em seus smartphones. Nesse sentido, eles não prestam atenção na explicação dela. Uma estratégia adotada pela professora para resolver esse impasse foi fazer um blog relacionado à disciplina. Além do blog, hospedado no wordpress, a docente alimenta uma página relacionada à disciplina no facebook e, igualmente, um perfil no instagram.

Conforme o conteúdo vai avançando, sínteses, vídeos, textos e informações relacionadas vão sendo postadas nesses três canais de comunicação que ela estabeleceu com os seus discentes. C2 constata que o canal que tem mais interatividade é a página hospedada na rede social facebook. E, de certo modo, o número de questionamentos dos alunos via Whatsapp aos finais de semana diminuiu.

Lúcia Santaella $(2010 ; 2013)$ tem tecido reflexões importantes sobre o tema aprendizagem ubíqua. A autora esclarece que o surgimento de uma nova tecnologia digital não elimina por completo a tecnologia já existente. A pesquisadora faz essa reflexão em resposta a algumas previsões eufóricas que acreditam na possibilidade da Aprendizagem Ubíqua - educação promovida via artefatos móveis, permitindo interação em qualquer hora, em qualquer lugar - vir a substituir a aprendizagem formal. 
Santaella não coaduna com essa perspectiva eufórica. Para a autora, a interação via artefatos móveis vem a complementar possibilidades no processo de ensino aprendizagem. A autora destaca que a educação não precisa abandonar elementos que a Pedagogia tradicional executou com tanta maestria: planejamento, didática, arguição oral. Ao contrário, esses elementos são cada vez mais necessários.

Para a pesquisadora, todas as formas de aprendizagem em curso na atual era tecnológica que estamos atravessando apresentam potenciais e limites. O grande desafio que se apresenta aos professores é analisar criticamente cada uma dessas possibilidades de interação e usá-las como complemento para alcançar a sua intencionalidade pedagógica.

Outro dilema apontado por jovens professores moderados sobre o uso de smartphones na sala de aula é o pré-conceito que a direção e a coordenação pedagógica têm sobre o uso pedagógico deste artefato. O Professor A2 destaca em sua narrativa, que a os laboratórios de informática nas escolas estaduais de São Paulo estão totalmente sucateados. Falta cadeira, falta monitor, sem falar nos artefatos quebrados que nunca são repostos.

Para A2 uma saída para esse problema é investir nos aplicativos e no uso pedagógico dos smartphones. O docente destaca que, $92 \%$ de seus alunos possuem celulares com sistema android, ou apple. Aparelhos estes que possuem conexão a internet. Todavia, o uso pedagógico deste artefato não é bem visto por seus colegas,

então diariamente a coordenação pedagógica me questiona, mas você vai utilizar o celular para explicar esse conteúdo tão complexo? E será que os alunos vão aprender? E eu digo, e por que você acha que o aluno vai aprender na Lousa e não vai aprender no celular? Então eu vejo que muitos colegas acreditam que o aluno só aprende com a aula tradicional, passando o conteúdo na lousa e o estudante copiando no caderno. Uma indagação que eu carrego comigo é porque não podemos fazer algo diferente? Aí muitos professores dizem, há mais aí você está matando aula. Eu não acho que é matar aula, é apresentar o conteúdo de uma forma diferente (sic) (Professor A2).

O docente de matemática destaca que há um discurso hegemônico, principalmente por parte da coordenação pedagógica, que o celular dispersa e tumultua a sala de aula. A2 enfatiza que sempre usou o artefato e alcançou resultados exitosos, o educador declara ainda que os trabalhadores da educação precisam ter autonomia para definir qual o melhor artefato a ser utilizado para uma determinada prática pedagógica.

Grapher, Matemática, Math Helper Lite, GeoGebra, foram alguns dos aplicativos citados pelo docente, como recurso utilizado para explicar fórmulas e conteúdos abstratos da disciplina de matemática. Para esse professor, a tecnologia digital permite tornar mais simples, conteúdos complexos como, por exemplo, a geometria espacial.

A2 enfatiza que essa posição é corroborada pelos vários mestrandos e doutorandos do OBEDUC $^{1}$ que ele recebeu nas turmas dos anos finais do ensino fundamental. De acordo com a narrativa docente, essas pesquisas tentaram explorar o uso de algum aplicativo em um conteúdo específico de matemática. Diante da infraestrutura sucateada na Rede Estadual de São Paulo, o uso pedagógico do artefato tecnológico do aluno tem se mostrado eficaz, além de permitir que o discente continue a manusear o aplicativo em outros espaços fora do ambiente escolar.

\footnotetext{
${ }^{1}$ Observatório da Educação, trata-se de um programa que é resultado da parceria entre a Capes, o INEP e a SECADI. Foi instituído pelo Decreto Presidencial no 5.803, de 08 de junho de 2006, com o objetivo de fomentar estudos e pesquisas em educação, que utilizem a infraestrutura disponível das Instituições de Educação Superior e as bases de dados existentes no INEP. O programa visa, principalmente, proporcionar a articulação entre pós-graduação, licenciaturas e escolas de educação básica e estimular a produção acadêmica e a formação de recursos pós-graduados, em nível de mestrado e doutorado.
} 
A dinâmica dos OBEDUCs também apareceu na fala do professor A3, que vê nesse projeto uma oportunidade incrível de elevar qualitativamente a formação continuada, além de aproximar a universidade da educação básica.

\footnotetext{
Com relação à formação continuada, acho que é investir em cursos nas escolas, a partir da realidade e da necessidade da instituição, geralmente a gente vê alguns acontecendo mais é por força da pesquisa ou da extensão universitária. Então você pega o OBEDUC, por exemplo, as escolas que tem parceria com o OBEDUC acabam tendo um acesso muito maior à formação para o uso das tecnologias. Então eu vejo que as escolas que acabam tendo iniciativas mais exitosas são por estarem próximas das universidades ou ser campo de Grupos de Pesquisa. Mas não é uma coisa que atinge todas as escolas de São Paulo, acaba pegando uma região ou outra. Acredito que se a dinâmica e a estrutura dos Observatórios da Educação atingissem todas as escolas, já seria um grande ganho para educação brasileira (sic) (Professor A3).
}

Os projetos de pesquisas em andamento envolvendo os Observatórios da Educação OBEDUC - ainda são muito recentes, uma avaliação mais profícua vai demandar pesquisas específicas. Mas de imediato é possível afirmar que a proposta de unir mestrandos, doutorandos e professores da educação básica para solucionar um problema específico de uma escola é uma perspectiva interessante.

A história recente do Brasil tem sido marcada por uma ausência da linearidade das políticas públicas. Ou seja, a cada novo governo, junto com a posse, temos a interrupção das ações iniciadas pelo governo anterior. É chegado o momento de superar essas fragmentações e encarar a educação como uma política pública de Estado.

\subsection{As narrativas dos Jovens Professores Iniciantes}

Essa categoria é formada por quatro docentes: B1, B2, B3 e, C3. Todavia, apenas a professora B1 aceitou conceder a entrevista. Os demais professores se colocaram à disposição para contribuir com a pesquisa, porém mediante resposta via questionário.

A participação via questionário traz algumas limitações para análise das narrativas: diferente do entrevistado, o participante via questionário teve um tempo para pensar e formular suas respostas; na análise não conseguimos mensurar se o participante teve dificuldade de discorrer sobre temas complexos, como por exemplo, vigilância na rede, cyberbullying; por fim, é preciso destacar que o questionário não me deu oportunidade de problematizar com o investigado, posições conflitantes em sua narrativa.

Os jovens professores iniciantes têm em comum o fato de terem concluído a licenciatura a menos de três anos e o ingresso na carreira do magistério ser muito recente. $O$ fato de três docentes se recusarem a conceder entrevista é um indicador relevante para o processo de investigação, demonstrando que esses jovens professores ainda têm muita insegurança para sustentar suas posições, bem como ainda estão em um estágio de reconhecimento das especificidades do âmbito escolar.

Três docentes - B2, B3, C3 - tiveram disciplinas na graduação que abordaram a integração das tecnologias digitais na prática pedagógica. A temática também foi explorada no estágio docência e na elaboração do TCC. Já a professora B1 teve uma disciplina optativa na graduação e, abordou a temática em um dos estágios na disciplina Pesquisa e Prática Pedagógica, bem como buscou aprofundamento na temática através de cursos extracurriculares.

Outro detalhe identificado nas narrativas dos jovens professores iniciantes é que quando eles precisavam trazer à tona exemplos práticos do uso das tecnologias digitais em situação de 
aula, eles recorriam as suas experiências desenvolvidas no estágio docência. O estágio é a grande referência para esses educadores.

Teve um caso específico que nos chamou a atenção pela temática que a docente abordou em sua pesquisa de TCC, alfabetização científica e redes sociais. Ficamos instigados em ler o trabalho de conclusão de curso dessa docente, como não encontramos o texto no repositório digital da universidade, enviamos um e-mail questionando se a professora poderia compartilhar o trabalho acadêmico, a docente gentilmente atendeu ao pedido.

A pesquisa exploratória da Professora B2 teve o objetivo de analisar o uso do Facebook como suporte didático para promover a alfabetização científica de estudantes na área de Física. A então graduanda buscou compreender o uso das redes sociais na atualidade e sua influência na área da educação científica. Outros objetivos da pesquisa foram: identificar as possibilidades de uso pedagógico da rede social com estudantes imersos ao universo virtual; compreender os sentidos atribuídos pelos estudantes com relação ao uso da rede social no processo de ensino e aprendizagem na área de Ensino de Física; refletir sobre o potencial das redes sociais na alfabetização científica dos estudantes de Ensino Médio.

Os dados da pesquisa foram coletados em três turmas do Segundo Ano do Ensino Médio durante a disciplina de Estágio II. A pesquisa envolveu sessenta e cinco estudantes de uma escola da rede estadual de ensino no município de Jaraguá do Sul/SC.

A Professora B2 constatou que os estudantes pesquisados tendem a realizar um uso "empobrecido" das potencialidades que a rede social oferece. Acerca desta temática, todos os jovens professores iniciantes informaram que qualquer atividade na escola com o objetivo de integrar as mídias, trata-se de um trabalho muito solitário. Seus colegas docentes são de outra geração, estes não vislumbram possibilidades com as TICs, bem como não tiveram formação para isso. Os jovens docentes respeitam e compreendem a postura de seus colegas.

Uma das conclusões do trabalho acadêmico da jovem educadora é que os estudantes aprendem a manusear as redes sociais através dos contatos informais do seu círculo social. Todavia, não é uma questão que é debatida na escola, por isso o não uso da rede social de forma crítica e transformadora. Em sua pesquisa de TCC, B2 constatou que os adolescentes pesquisados estão em um lócus, onde culturalmente a rede social é utilizada para jogos e entretenimento. Para a docente, a escola de certo modo corrobora com essa perspectiva ao não explorar as potencialidades pedagógicas.

B2 advoga a necessidade de mudanças na forma de uso e acesso das redes sociais no âmbito escolar, sobretudo tratando-se de jovens que vivem imersos ao ciberespaço. É preciso uma reorganização curricular, visando o uso das redes para debate em torno de questões científicas, que possibilite a tomada de decisões responsáveis na vida cotidiana.

Bonilla e Pretto (2015) analisaram o professor e as práticas pedagógicas no âmbito da cultura digital em duas escolas de educação básica de Santa Catarina (Florianópolis e Jaraguá do Sul), e duas escolas na Bahia (Salvador e Itabuna). Constataram que a maioria dos docentes não consegue perceber as potencialidades e possibilidades de uso das redes sociais e ambientes virtuais em situação de aula. Na ampla pesquisa realizada pelos pesquisadores o máximo que ocorria era,

liberar os alunos para jogar, desenhar ou utilizar as redes sociais após o término das tarefas, consideradas como pedagógicas, como se jogar, desenhar e utilizar redes sociais não pudessem ser também atividades pedagógicas. A falta de percepção sobre as potencialidades comunicacionais e de imersão na cultura digital dos ambientes interativos da Web 2.0 para as atividades desenvolvidas na escola leva muitas delas a bloquear as redes sociais, e esse bloqueio inviabiliza a realização de projetos envolvendo 
diálogo entre turmas diferentes, ou entre os alunos e outras pessoas, externas à escola, o que potencializaria processos de aprendizagem baseados na troca, na interação dinâmica e colaborativa, no compartilhamento de ideias e saberes (BONILLA e PRETTO, 2015, p. 512).

$\mathrm{Na}$ observação participante que os autores realizaram nessas instituições de ensino, foi identificado que a restrição da escola a redes sociais, instigava os alunos a investirem no conhecimento sobre tecnologia da informação e comunicação para driblar o bloqueio. Trata-se da cultura do hackerativismo emergindo no 'chão da escola'.

Esse movimento cultural surgiu a partir da necessidade de resolver problemas tecnológicos complexos. Os jovens estudantes, mesmo sem conhecer os princípios que norteiam a cultura do hacker, incorporam algumas práticas desse movimento ao agirem na perspectiva de liberar o acesso ao ciberespaço.

Entre os jovens professores iniciantes, B1 foi a única docente dessa categoria que aceitou conceder entrevista. Estava ansioso, pois B1 foi indicada por B0, esta acreditava que a docente poderia trazer contribuições relevantes para a pesquisa, pois a profissional trabalha em uma escola privada do município de Florianópolis que é reconhecida socialmente por ser tecnológica.

$\mathrm{Na}$ entrevista tive a oportunidade de compreender que na verdade a escola utiliza um material didático fornecido por uma editora. Junto com o material impresso, a editora disponibiliza uma plataforma educacional, hospedada no ciberespaço que pode ser acessada por alunos e professores.

Neste ambiente virtual, se o internauta entra com o perfil de aluno, este terá acesso a vídeos, imagens e, jogos educacionais correspondentes ao ano/série que o estudante está cursando. Se o perfil de acesso é professor, o usuário terá alguns recursos de suporte para ministrar determinado conteúdo.

B1 atuava no segundo ano do Ensino Fundamental, e uma das suas primeiras reflexões foi sobre a falta de estrutura na escola. De acordo com a narrativa docente não existia na instituição, por exemplo, um laboratório de informática. Quando ela precisava fazer alguma atividade pedagógica de integração com as mídias, a educadora retirava na coordenação pedagógica um laptop e um datashow para utilizar em sua sala de aula.

Para a professora isso é "subutilizar a tecnologia, é não explorar as potencialidades da tecnologia digital. É agir a partir da realidade analógica já existente" (Professora, B1). De acordo com a docente, uma das sugestões da editora era que a escola adquirisse alguns Tablets para que os alunos pudessem interagir colaborativamente no ambiente virtual, mas a direção ainda estava analisando tal proposta.

Em sua narrativa, a docente destaca ter observado alunos de oito anos com perfil no facebook. B1 constatou ainda que, os pais usavam com intensidade as redes sociais digitais, esse comportamento, de certa forma, instigava os filhos a manusear o ciberespaço. É preciso ressaltar que a fala da professora se refere a famílias de alto poder aquisitivo na cidade de Florianópolis.

Quando solicitado que a docente descrevesse uma prática pedagógica com integração das mídias na sala de aula, quase todos os exemplos se referiam ao uso de vídeos ou imagens para exemplificar algum detalhe abstrato abordado no conteúdo. B1 trouxe à tona também exemplos do seu estágio docência, tendo em vista que fazia apenas dois anos que ela havia concluído a graduação.

Ao relatar algumas práticas do estágio, sua fala foi constituída de uma riqueza de detalhes demonstrando a relevância do estágio docência para a constituição da subjetividade professoral: o frio na barriga por estar na regência de classe pela primeira vez; o desafio de uma prática pedagógica colaborativa com produção de vídeos em uma instituição que não tem tradição de 
uso das TICs; a importância do trabalho em equipe com os outros colegas que também realizavam o estágio docência; o conforto de poder dividir as angústias vivenciadas na sala de aula com a orientadora e com a supervisora de estágio.

Por fim, as análises de todas as narrativas docentes - vanguardistas, moderados e iniciantes - demonstram ainda que a participação do licenciando em projetos de pesquisa ou extensão universitária fez uma grande diferença na formação desse jovem docente. A experiência prática do estágio docência e da extensão, juntamente com as reflexões teóricas da iniciação científica faz com que esse jovem, agora professor, tenha mais subsídios para lidar com a imprevisibilidade e as especificidades da sala de aula.

\section{ENFIM, O QUE SABEMOS SOBRE A DOCÊNCIA CONECTADA?}

Compreender o papel da educação na contemporaneidade significa empreender esforços para avaliarmos esteticamente essa era tecnológica que estamos atravessando, bem como analisarmos criticamente como essa sociedade, conectada por redes digitais, está impactando a nossa subjetividade.

Nesse sentido, a obra de Guatarri $(1992 ; 1993)$ nos oferece subsídios importantes para desvendar a complexidade da engenharia da informação, assim como os novos processos subjetivos mobilizados pelas redes digitais. Para o autor, não se pode analisar a atual sociedade sem levar em consideração "a influência invasiva da assistência do computador, dos bancos de dados, das redes telemáticas" (p. 177). O francês reconhece o paradoxo inaugurado pela disseminação dessas redes: abismo entre os que detêm a riqueza e os que não têm os elementos básicos de subsistência; uma aparente transparência nos dados e na informação ao mesmo tempo em que ocorre um enclausuramento frenético entre as instâncias que produzem e detêm a informação; conflitos entre o público, privado, profissional e social.

Para o autor, os sistemas informáticos nada mais são do que: formas hiperdesenvolvidas, hiperconectadas, hiperconcentradas da subjetividade humana. Nesse sentido, não há razão para negar ou desviar-se da tecnologia. O grande desafio que está posto é compreender os jogos de poderes que estão estabelecidos nessa sociedade conectada por redes e encontrar formas de romper com esse estado de opressão, nas palavras do autor:

A subjetividade permanece hoje massivamente controlada por dispositivos de poder e de saber que colocam as inovações, técnicas, e artísticas a serviço das mais retrógradas figuras da sociedade. E, no entanto, é possível conceber outras modalidades de produção subjetiva - estas processuais e singularizantes. Essas formas alternativas de reapropriação existencial e de autovalorização podem tornar-se, amanhã, a razão de viver de coletividades humanas e de indivíduos que se recusam a entregar-se à entropia mortífera, característica do período que estamos atravessando (1993, p. 190-191).

A hiperconexão de sistemas, plataformas e artefatos tecnológicos, atrelada à mobilidade da comunicação contemporânea, está produzindo novos processos de subjetivação. Nesse sentido, a obra de Guatarri se apresenta como oportuna para problematizarmos o conjunto de pontos - redes - que nos interconectam com as questões da educação contemporânea e nos desafiam a estar sempre atentos à evolução dessa sociedade em rede (CASTELLS, 2002; 2010; 2015).

A utilização das redes sociais, para facilitar e criar mais oportunidades de interação e aprendizagem colaborativa, é uma questão sobre a qual temos nos debruçado com o grupo de pesquisa com o qual trabalhamos. O papel e o lugar dos trabalhadores da educação passam por 
mudanças importantes na contemporânea geração do conhecimento e das tecnologias digitais. Parafraseando Freire (1993):

\begin{abstract}
Não nasci marcado para ser um professor assim (como sou), vim me tornando desta forma no corpo das tramas, na reflexão sobre a ação, na observação atenta a outras práticas, na leitura persistente e crítica. Ninguém nasce feito, nos fazemos aos poucos, na prática social que tomamos parte (p. 79-80).
\end{abstract}

No árduo desafio de tentar compreender essa sociedade interconectada por redes e mediada por tecnologias digitais, este estudo teve o propósito de provocar os educadores a refletirem sobre novos elementos que emergem na cultura contemporânea, e que influenciam cotidianamente a relação docente-estudante em situação de aula, bem como no exercício da cidadania.

A análise das doze narrativas demonstrou que o fato dos jovens professores terem uma tendência maior em usar artefatos tecnológicos em sala de aula, não está relacionada somente a questão de eles serem jovens nascidos em uma sociedade de ampla difusão de redes e artefatos tecnológicos digitais. O fator principal que impulsiona as práticas desses professores é a aproximação que eles tiveram com a área na licenciatura e um aprofundamento na temática via curso extracurricular, formação continuada e pós-graduação. As ambivalências, paradoxos, inacabamentos e contradições identificadas nas narrativas docentes, trazem à tona o quanto precisamos avançar sobre as discussões das tecnologias digitais nos currículos que formam professores.

\title{
5 REFERÊNCIAS
}

BIERNACKI, P., WALDORF, Dan. (1981) Snowball Sampling: Problems and Techniques of Chain Referral Sampling. Sociological Method Research. V.10, p. 141-163.

BONILLA, M. H. S., PRETTO, N. L. (2015) Política Educativa e Cultura Digital: entre práticas escolares e práticas sociais. PERSPECTIVA, Florianópolis, v. 33, n. 2, p. 499 - 521.

BRASIL. Presidência da República. Secretaria de Comunicação Social. Pesquisa brasileira de mídia 2015: hábitos de consumo de mídia pela população brasileira. Brasília: SECON, 2014.

. LEI № 12.852, de 5 de agosto de 2013. Institui o Estatuto da Juventude e dispõe sobre os direitos dos jovens, os princípios e diretrizes das políticas públicas de juventude e o Sistema Nacional de Juventude - SINAJUVE. Disponível em: $<$ http://www.planalto.gov.br/ccivil_03/_Ato2011-2014/2013/Lei/L12852.htm>. Acesso em: 25 jan. 2015.

BURBULES, N. C. (2013) Los significados de "aprendizaje ubicuo". Archivos analíticos de políticas educativas, 22 (104). 2014. Http://dx.doi.org/10.14507/epaa.v22.1880. Arículo publicado originalmente en: revista de política educativa, año 4, número 4, udesa-prometeo, buenos aires.

CASTELLS, M. (2002) A Sociedade em rede - a era da informação: economia, sociedade e cultura. v.I. São Paulo: Paz e Terra.

. (2010) Communication Power. Cambridge, MA: MIT.

(2015) O Poder da comunicação. São Paulo: Paz e Terra.

CITELLI, A. O., COSTA, M. C. C. (2011) Educomunicação: construindo uma nova área de conhecimento. São Paulo: Paulinas.

DEWES, J. O. (2013) A amostragem em Bola de Neve e Respondent-Driven: Uma descrição dos Métodos. 2013. 63 f. TCC (Graduação) - Graduação em Estatística, Instituto de Matemática, 
Universidade Federal do Rio Grande do Sul, Porto Alegre.

DUSSEL, I. (2011) VII Foro Latinoamericano de Educación: aprender e ensinar en la cultura digital.

1.ed. Buenos Aires: Santillana.

(2010) La invención pedagógica del aula: Una genealogía de las formas de enseñar.

Buenos: Ed. Santillana.

- (2013) Curriculum y Autoridad Cultural: Metáforas para pensar en los desafios contenporáneos. In: MORGADO, José Carlos; SANTOS, Lucíola Licínio de Castro Paixão; PARAÍSO, Marlucy Alves. Estudos Curriculares: Um debate contemporâneo. Curitiba: CRV. p. 11-36.

ERICKSON, F. (1992) Ethnographic microanalysis of interaction. LECOMPTE, M. D., MILLROY, W. L.; PREISSLE, J. (Ed.). The Handbook of Qualitative Research in Education. New York: Academic Press, p. 201-226.

Freire, P. (1976) Extensão ou Comunicação? Rio de Janeiro: Paz e Terra. (1993) Política e Educação. São Paulo: Cortez.

GUATTARI, F. (1992) Caosmose. Um novo paradigma estético. Ana Lúcia de Oliveira e Lúcia Cláudia Leão (Trads.). Rio de Janeiro: Ed. 34.

(1993) Produção de subjetividade. In: PARENTE, A. (Org.). Imagem Máquina. Rio de Janeiro: Ed. 34.

GEERTZ, C. (1989) A interpretação das culturas. LTC: Rio de Janeiro.

GOODMAN, L. A. (1961) Snowball Sampling. Annals of Mathematical Statistics. v.32, p.148-170. Disponível em: http://projecteuclid.org/DPubS?verb=Display\&version=1.0\&service=UI\&handle=euclid.aoms /1177705148\&page=record Acesso em: 04 Sep. 2015.

HARAWAY, D. (1991) Cyborg manifesto: science, technology and socialist feminism in the late twentieth century. In: Simians, cyborgs, and women: the reinvention of nature. New York: Routledge.

(2009) Manifesto ciborgue: ciência, tecnologia e feminismo-socialista no final do século XX. In: SILVA, Tomaz Tadeu da. Antropologia do ciborgue: as vertigens do pós-humano. 2.ed. Belo Horizonte: Autêntica, p. 33-99. (MIMO).

KERCKHOVE, D. (2016) Ética de transparência na era do Big Data. In: LOPES, Maria Immacolata Vassallo de; KUNSCH, Margarida Maria Krohling. Comunicação, cultura e mídias sociais. São Paulo: ECA USP, 2016. p. 5-23.

LÉVI-STRAUSS, C. (1988) Tristes trópicos. Barcelona: Paidós.

LÜDKE, Menga; ANDRÉ, (1986) Marli Elisa Dalmazo Afonso. A Pesquisa em educação: abordagens qualitativas. São Paulo: EPU.

LUNARDI-MENDES, G. M; SOUZA NETO, A; REIS, V. (2015) Laptops na sala de aula: os desafios da escola em tempos digitais. In: BUSARELLO, Raul Inacio; BIEGING, Patricia; ULBRICHT, Vania Ribas (Orgs.). Sobre Educação e Tecnologias: conceitos e aprendizagem. 1.ed., v.1, São Paulo: Pimenta Cultural, p. 145-159.

MALINOWSKI, Bronisław. (1978) Uma teoria científica da cultura. Rio de Janeiro: Zahar.

MATTOS, C. L. G. (2011) A abordagem etnográfica na investigação científica. In: MATTOS, CLG., and CASTRO, PA., orgs. Etnografia e educação: conceitos e usos. Campina Grande: EDUEPB. pp. 49-83.

MEHAN, H. (1992) Understanding inequality in schools: the contribution of interpretative studies. Sociology of Education, v. 62, no 1, p. 265-286.

MINAYO, M. C. S. (2014) O Desafio do Conhecimento: Pesquisa qualitativa em saúde. 14 ed. São Paulo: Hucitec Editora. 
QUARTIERO, E. M., FANTIN, M. (2014) Education-Research in School: places and authorships in question. REM- Research on Education and Media, v. 6, p. 35-45.

QUARTIERO, E. M., BONILLA, M. H., FANTIN, M. (2015) Projeto UCA: entusiasmos e desencantos de uma política pública. 1.ed., v.1. Salvador-BA: EDUFBA, 241p.

SALES, S. R. (2013) O imperativo da ciborguização no currículo do ensino médio. In: MORGADO, José Carlos; SANTOS, L. L. C. P., PARAÍSO, M. A. Estudos Curriculares: um debate contemporâneo. Curitiba: CRV, p. 193-206.

- (2012) Etnografia+netnografia+análise do discurso: articulações metodológicas para pesquisar em educação. In: MEYER, D. E., PARAISO, M. A. Metodologias de pesquisas póscríticas em educação. Belo Horizonte: Mazza Edições, p. 111-132.

SANTAELLA, L. A cultura digital na berlinda. In: LOPES, M. I. V., KUNSCH, M. M. K. Comunicação, cultura e mídias sociais. São Paulo: ECA USP, 2016. p. 93-101.

. (2013) Comunicação ubíqua: repercussões na cultura e na educação. São Paulo: Paulus.

- (2004) Navegar no Ciberespaço: o perfil cognitivo do leitor imersivo. São Paulo: Paulus.

- (2010) A aprendizagem ubíqua substitui a educação formal?. ReCeT: Revista de Computação e Tecnologia da PUC-SP, v. 2, p. 17-22.

WILLIS, P. (1977) Learning to labor: working class kids get working class jobs. Farnborough, Eng: Saxon House.

WOODS, P. (1986) Inside schools. Ethnography in educational research. London: Routledge.

YOUNG, M. F. D. (2010) Conhecimento e currículo: do socioconstrutivismo ao realismo social na sociologia da educação. Tradução de Jorge Ávila de Lima. Porto: Porto Editora. 